\title{
NORTHEAST ASIAN ECONOMIC COOPERATION AND ECONOMIC DEVELOPMENT OF INNER MONGOLIA : SITUATION AND PROSPECTS
}

\author{
Enkhee \\ Research Institute of Neighboring \\ Countries, Inner Mongolia University,
}

China

Since the mid 1980s, regionalization and grouping have become the general trend of world economic development. With the end of the cold war, relations between countries in Northeast Asian region have been improved gradually. Frequent activities of "Northeast Asian Forum" has concretized the conception of "Northeast Asia Economic Rim" and helps it move toward cooperation. Since Inner Mongolia began to implement its strategy "driving the overall situation by opening to the outside world" in the early 1990s, it has started economic cooperation with other provinces and regions, especially with coastal provinces of the country on one hand, and it has opened up to the outside world in all bearings, as a result of which, its merchandise trade and

Economic and technical cooperation with foreign countries have made considerable progress. During this period, the economists of Inner Mongolia participated in the '95 Beijing Conference and '97 Changchun Conference, both being concerned with the problems of developments of cooperation $\%$ in Northeast Asia. This is a manifestation that Inner Mongolia has began to give need to the progress of cooperation in Northeast Asian and been searching opportunities of development from the regional cooperation.

\section{The Role of Inner Mongolia in Regional Cooperation in Northeast Asia}

The Mongolian plateau which includes Inner Mongolia embraces four advantages in participating in Northeast Asian cooperation:

\section{1 -1 The Advantage of Location}

The Mongolia plateau itself is in the only passing way of Euro-Asia land bridge. With regard to Inner Mongolia, it is a narrow region extending from east to west with 8 neighboring provinces and regions at home and having over 4200 kilometers of boundary line with Russia and Mongolia. Since the reform and the opening - up, the ports construction has essentially been strengthened, and the number of land route ports has been reached 18 with a goods transit capacity of 
over 9 million tons per year. Ashen Port and the construction of its auxiliary facilities have drawn the attention of Chinese government and international community.

\section{1 -2 the Advantage of Nationality}

Most of the Mongolian nationality of the world lives in Inner Mongolia of China. Mongolia and several republics in the south of Russia. When the three countries open wider to each other, mutual learning and exchange will inevitably be enhanced in the process of social economic development. The similarities in traditional culture and economic structure will also serve as an impetus to the development of economic relations.

\section{1-3 the Advantage of Resources}

The whole Mongolian Plateau is one of the areas abundant with natural resources in the world. Inner Mongolia has been well known for its "forest in the east, iron in the west, grain in the south and animal husbandry in the north, and mineral resources everywhere."More than 130 minerals of various kinds have been discovered, 56 of which rank the top 10 in China and 29 the top three. The reserves of rare-earth elements rank the first in the world while that of coal the second in China. The complementarities of the factors of productive forces in Northeast Asian countries require developing and utilizing the natural resources in Inner Mongolia. The Northeast of China that have already taken an active part in exploring the possibility of economic cooperation in Northeast Asia, esp. those mineral-lacking provinces such as Liaoning and Jilin, will rely, to a greater extent, on Inner Mongolia's coal and electricity resources. Forest, pasture and natural environment of Inner Mongolia will supply "green food" to not only for some areas of the Northeast, but also for the some countries in NEA.

\section{1-4 Favorable Policies}

The essential policy for Inner Mongolia's economic development is to open to the outside world firmly and unshakably and nowadays, the openingup is in the direction of "a wider fields an all-round way and at a higher level". "Opening up-development" has become one of the five strategies in the implementation of "The Ninth Five-Year Plan for Social and Economic Development and the Long-term Programmed for 2010" of the Autonomous Region. To realize economic development of Inner Mongolia, the only way is adhering to the opening up to each other among the countries within the region, promoting bilateral and multilateral economic cooperation and gradually improving the level of cooperation in the whole region. 


\section{Significant Progress in Inner Mongolia's Economic Relations with} the Intraregional Countries

\section{2-1 Northeast Asia Has Become the Major Region Where Inner Mongolia carries out its Foreign Trade}

It has been proved by international experience that no country or region can achieve its economic prosperity without developing economic relations with foreign countries and without participating in the systemic circulation in world economy. And the initial step to develop economic relations with foreign countries its inevitably expanding foreign trade. As the national policy of opening to outside world has been firmly implemented, beginning from the mid 1980s, especially in the 1990s, Inner Mongolia has made great achievement in its foreign merchandise trade. During the 11 years from 1986 to 1997, its total turnover, import volume and export volume in foreign trade have been steadily increased by an average annual growth of $17.4 \%, 24.3 \%$ and $14.2 \%$ respectively, but the total turnover and the export volume in trade with NEA countries have exceeded the previous corresponding figures by 1.9 and 2.7 percentage points respectively. ${ }^{1}$ Moreover, the proportion of the trade with NEA countries in Inner Mongolia's trade has been rising sharply, as Table 1 shows:

Table1. Proportion of Trade with the Intraregional Countries in Inner Mongolia's Foreign Trade as a Whole (\%)

Source: Inner Mongolia's Statistical Yearbooks, various years.

Table 1 show that by the end of 1980s, Inner Mongolia's trade with NEA countries makes up more than half of its total volume of the foreign trade and by the time of 1993 , it amounts to $2 / 3$ of the total volume. Though the proportion fluctuated in the years after 1993 due to the domestic economic situation in 
Russia and Mongolia, Inner Mongolia's trade relations with NEA countries are becoming even closer, a fact that has become non-reversible trend.

\section{2-2 Significant Progress Has Been Made in Economic Cooperation with the Intraregional Countries}

The Inner Mongolia began its external economic cooperation in 1988, at first with neighboring countries like Mongolia and Russia and then extended to Japan and other countries outside Northeast Asian region. From 1988 to 1997, Inner Mongolia has signed contracts for international engineering with some intraregional countries, the contract amount of which exceeded 54 million USD with annual average growth of $39.1 \%$; a turnover of more than 348 million USD was made with annual average growth of $39.3 \% ; 45.517$ laborers were sent abroad; 9 aid projects to Mongolia by the Chinese government have been carried out, assistance contribution to which reached 3.51 man USD;228 enterprises in Mongolian and Russian territory were examined and approved, in which investment by Inner Mongolia amounting to $51.55 \mathrm{mln} \mathrm{USD}^{2}$.

\section{2-3 the Intraregional Countries' Capital Has Began Inflow into Inner Mongolia}

To replenish the shortage of funds and to realize the increase of economy, an important thing for developing countries to do, especially for less develop areas like Inner Mongolia to do is to draw and introduce foreign investment in great amount. By the end of last year, some intraregional countries like Japan, Korea have offered government loan to Inner Mongolia, providing $204.27 \mathrm{mln}$ USD for the implementation of 6 projects. The number of joint ventures invested by Northeast Asian countries' businessmen reached 221; the foreign direct investment reached $129.76 \mathrm{mln} \mathrm{USD}^{3}$. It is definitely sure that, the capital invested by Northeast Asian countries has played a very important role in helping Inner Mongolia which is in the primary stage of socialism to transform the former ownership structure, to improve the technical and equipment level, to establish a modern system of enterprise.

\section{The Idea and Measures in Participating in Northeast Asian Economic Cooperation}

\section{3-1 Basic Idea}

In participating in the economic cooperation in NEA, the basic idea that Inner Mongolia will embrace is making full use of its characteristic advantages and implementing the strategic policy of "opening in the direction of a wider field, in an all-round way and at a higher level"; and with both domestic and foreign capital and facing both domestic and international markets; will take an 
active part in the regional division of labor so as to speed up the increase of economy in Inner Mongolia.

\section{3-2 Major Measures}

\section{3-2-1 Open up Further in an All-round Way}

Inner Mongolia, as an economically less developed area in China, has linked its own development with the implementation of strategic opening to the outside world, which can be divided into two parts-domestic opening to other provinces and regions and opening to foreign countries. The domestic opening means that according to the law of market economy with establishing regional economy in mind, we will break down the boundary of administrative area to combine our superiority of natural resources and industry with that of capital, technology and management of the developed and coastal areas and neighboring regions so as to realize mutual complementarily of superiority, mutual benefit of interest and mutual development. To develop economic and technical cooperation with the northeast provinces of China and to participate in the economic cooperation of the Bohai Sea Rim region is, among others, not only important opportunities for economic growth in Inner Mongolia, but also a component part of the economic cooperation in NEA as a whole.

Another important aspect of the opening to the outside world is strengthening the bilateral and multilateral economic relations with NEA countries and other countries of the world. During the period of the "9 the Five-Year Plan", Inner Mongolia will continue to export textiles and other light industrial products as its chief export goods and develop in the direction of electromechanical and high-energy-consuming products, and endeavor to obtain the proportion of $62 \%$ by manufactured goods in export total by the year 2000. In order to develop the economic relations with NEA countries, we will try to maintain and expand market share of the export goods like food products, coal, etc. in NEA and at the same time import advanced technology and equipment from the intraregional developed or newly industrialized countries.

\section{3-2-2 to improve the "Hard" and "Soft" Environment for Attraction and Utilization of foreign Capital}

To bring about a greater development in Inner Mongolian border area, will reinforce, at the time of adjusting the distribution of productive forces, the construction of ports of various kinds. While centering on the construction of ports, we will also make a rational distribution of the infrastructure such as transport, communication facilities so that favorable conditions for land-sea combined transport passageway would be created and the Northeast Asian 
transnational economic zone, the surrounding economic region of the Bohai Sea and other coastal provinces could do business with Russia, Mongolia and East Europe through the border areas of Inner Mongolia. To this end, Manchuria, China's biggest land rout port, will be built into an important international trade city in the Northeast Asian transnational economic region with a railway and highway goods transit capacity of $10 \mathrm{mln}$ tons; Ereen port will be built into an important hub of communications, a landsea combined transport passageway for the surrounding economic region of the Bohai Sea to enter Mongolia, Russia and East European countries, its transit capacity reaching $8 \mathrm{mln}$ tons; the ground infrastructure of Huhhot airport will be improved and new international airlines will be opened. By the time of next century, Arshan land route port will be built into a hub of international land-sea combined transport passageway with Hunchun-Changchun-Arshan-Choibalsan-Chita as its passage. ${ }^{5}$

To accommodate the construction of these ports, railroads and highways that can connect Inner Mongolia with they will be built and several domestic and international transport passageways will be opened. Based on the demand of market economy, we will, at a higher starting point, accelerate the development of post and telecommunication industry and by the turn of the century, every village will be accessible by postal communication, the total capacity of telephone exchange being $3 \mathrm{mln}$ with a popularization of $8 \%{ }^{6}$, thus a favorable "hard" environment may be created to attract more foreign capital.

Fundamentally speaking, the most important "soft" climate for further participation in international cooperation is the rapid establishment of socialist market system. Since the 15 th National Congress of CPC, a strategic restructuring of state-owned enterprises in Inner Mongolia has been expedited. It is estimated that in two years' time, reformation of capital such as joint-stock system and share-cooperative system will serve as the implementing form of public ownership while the proportion of non-public ownership will be greatly increased in national economy as a whole. Mean-while, in accordance with the principle of "separate government from enterprise functions", the function of the government will be averted for formulating policies and plans for the economic and social development, strengthening the macro control over the economic operation so that a new mechanism that the government regulates and control market and guides enterprises will be formed.

\section{3-2-2 to Further Reform the System of Foreign Trade}

In order to give aid to a great number of enterprises which, without relying on the government, can operate independently and specializes in producing and circulating commodities for international trade, the government of the au- 
tonomous region encourages large and medium-sized enterprises to set up working body abroad. Those enterprises, which have certainly prospects in export trade, will be given

Export authorization and can operate on their own. It is hoped that by he year 2000 , there will be about 230 enterprises and companies ${ }^{7}$ having such authorization. The implementation of the above measures will undoubtedly further enable Inner Mongolia's participation in the Northeast Asian economic cooperation and play a very important role in connecting the economy of the autonomous region with that of the international.

\section{Steps of Participating in the Northeast Asian Economic Cooperation}

The prospects and steps of Inner Mongolia's participation in the NEA cooperation are determined by the development and progress of the regional cooperation and by the internal condition of Inner Mongolia.

The Northeast Asian economic cooperation, when its development and progress are considered, differs from that of EU and that of NAFTA, and at the present time and in a considerable long time to come, it cannot develop into a relatively closely-knit cooperation entity. Scholars from many countries generally agree that one of the major characteristics of the cooperation in this region is the looseness of the cooperation organization and its opening-up to countries outside the region. There are indications from the cooperation so far that with the only exception of the Tumen River Valley Project which is a contractual cooperation signed by the government of relevant countries, all the other cooperative developments are of bilateral and multilateral cooperation impelled by marketing function. But as far as Inner Mongolia is connected, its participation in the NEA cooperation is still in the primary stage of functional cooperation, up to now being chiefly restricted to developing bilateral cooperation with countries within the region. The main features are:

Co-existence of vertical and horizontal divisions of labor. Inner Mongolia's trade and economic cooperation with countries and areas of similar development level are of the horizontal, while the cooperation with Japan and South Korea are of vertical.

Inner Mongolia is an area which is, on one hand, abundant with natural resources but is less developed, and which, on the other hand, is very short of capital and technology.For this reason, an investment-guided development pattern will be more appropriate to the condition of Inner Mongolia.

The conditions mentioned above have determined the stages of Inner 
Mongolia's participation in the Northeast Asian economic cooperation, namely at the first stage, making comprehensive opening to economically developed regions and coastal provinces at home and to foreign countries, including those in NEA so as to promote bilateral cooperation; then at the second stage, making deeper integration with the cooperation of this region. Of the two stages, the first is the basis and prerequisite for the cooperation. As regards to the economic cooperation with the Northeast Asian countries, the following points will be achieved:

\section{4-1 Further Expanding Trade with the Northeast Asian Countries.}

In the few years to come, the total turnover of the Autonomous Region will be increased by $12.2 \%$ yearly and by the time of the year 2000 , it will amount to 2 billion USD, in which the export will grow at an annual average rate of $11.8 \%$ and will reach $940 \mathrm{mln}$ USD. Taking into consideration of import increase when China joins WTO, there will be a balance of import and export after the year 2000 . Efforts will be made to improve export mix with the proportion of manufactured products being increased to $62 \%{ }^{8}$.It is estimated

that the Inner Mongolia's trade with the Northeast Asian countries will be on a moderate increase and the export of electromechanical products, and textiles and other light industrial goods will be increased remarkably. Macro-regulation of foreign trade will be made to strengthen the administration and guidance of import-while guaranteeing the proportion of import goods that is of vital important to the national economy and people's livelihood, attention will be paid to import advanced technology and equipment and import restrictions made on luxury goods.

\section{4-2 Paying Attention to Draw More Foreign Capital and Increasing its Utilization Ratio}

In accordance with the economic development strategy and industrial policy formulated by the government of Inner Mongolia, considering the payment of debt, for the purpose of the integration of the autonomous region's economy into international economic cycle, Inner Mongolia will speed up its steps to attract foreign capital and increase its function played in industrial restructuring. According to the plan of the autonomous region's government, during the whole period of "9th Five-Year Plan", the total of indirect foreign capital utilized will be increased by $618.8 \%$ over that of the "8th Five-Year Plan" period, amounting to about 4.6 billion USD, of which more than $43 \%$ will be realized by getting government loans or bank loans from the Northeast Asian countries. During this period, of the 1.4 billion USD that might be obtained by 
direct foreign investment, a great proportion will come from investors of the Northeast Asian countries. The chief utilization of foreign capital will be shifted to the construction of infrastructure such as water supply in city, environmental control, transportation, communication, energy construction, building materials, chemical industry and comprehensive development of agriculture and animal husbandry. The funds will also be used in the transformation of old enterprises, to introduce advanced technology and to develop new and high technological industry. However, special attention will be paid to get the foreign direct investment being used in the large and medium-sized projects that are decisive in the whole economic development.

\section{4-3 Ensuring a Sustained Development of Economic Cooperation with Foreign Countries}

International economic cooperation has always been a two-way cooperation when considered from a long-term point of view. In the two years coming towards the turn of the century, Inner Mongolia will continue to implement its strategy of opening to the region's bordering areas and open up international market. In order to steadily develop the engineering contract and the cooperation in the field of labor service abroad, efforts will be made to gradually transform the cooperation from mainly in the field of labor service to mainly in international engineering contract; and in international engineering, from sub-contract to general contract. At present Inner Mongolia is undertaking 9 China's aid projects for Mongolia and in the past 10 years 144 Inner Mongolia-Mongolia's joint ventures have registered in Mongolia. To complete these projects on schedule with guaranteed quality and to encourage these enterprises to play a positive role in Mongolian economic growth will still be the mission of Inner Mongolia in the bilateral economic cooperation.

\section{Suggestions}

Several seminars have been held since the appearance of "Northeast Asian Economic Cooperation Forum.' It has been agreed by all that the cooperation potential in this region is great and future bright, however, the practical process of cooperation is not as satisfying. The actual cause may be traced to the fact that effective mechanism for cooperation has not been formed yet. In order to form such a mechanism, the writer suggests:

5-1 urging more high-ranking officials to participate in the Forum and to pay more attention to the progress of cooperation. It has been proved by international experience that without the participation of the countries' governments 
concerned, institutionalized cooperation mechanism can not be formed, and thus no substantial progress can be made in regional cooperation. Therefore, it has become extremely urgent to have high-ranking officials' participation and to persuade the governments concerned to work out foreign policies which will attach high priority to the cooperation in NEA with the advent of the 21 sty century.

5-2 Improving investment environment including policy making in capital absorbing countries and regions. Efforts should be made to reduce the risk of investment and cut short the time period for recovery of investment; market mechanism should be further perfected, flexible economic cooperation policy be carried out and domestic infrastructure construction be expedited. But investors should notice that the less developed countries and areas in the region have made considerable achievements in the above-mentioned aspects, so with foresightedness and broad mind, they should make strategic decisions in terms of long-term investment and technology transfer.

5-3 An impetus to the rapid progress of the regional cooperation is still that to strengthen social and cultural exchange and cooperation between the countries in order to improve mutual understanding, to clear up the misunderstanding that in fact exists and to seek for the common ground for cooperation.

\section{Notes:}

1 Calculated according to the Statistical Data on Inner Mongolia's Foreign Trade \& Economics, relevant years.

2. 3. Ibid.

4. Inner Mongolia Autonomous Region Planning commission, "The Ninth Five-Year Plan for Social and Economic Development and Long-term Objectives for 2010", Inner Mongolia Publishing House, 1997 5.6.7.8. Ibid. 